\title{
Preference of larvae of Enallagma cyathigerum (Odonata: Coenagrionidae) for habitats of varying structural complexity
}

\author{
RALF C.M. VERDONSCHOT ${ }^{1}$ and Edwin T.H.M. PEETERS ${ }^{2}$
}

\author{
${ }^{1}$ Department of Freshwater Ecology, Centre for Ecosystem Studies, Alterra, Wageningen UR, P.O. Box 47, 6700 AA, Wageningen, \\ The Netherlands; e-mail: ralf.verdonschot@wur.nl \\ ${ }^{2}$ Department of Aquatic Ecology and Water Quality Management, Wageningen University, P.O. Box 47, 6700 AA, Wageningen, \\ The Netherlands
}

Key words. Enallagma cyathigerum, habitat complexity, macroinvertebrate-macrophyte interaction, Zygoptera, phytomacrofauna, two-choice experiment

\begin{abstract}
In macrophyte-rich lentic ecosystems, higher numbers of damselfly larvae occur in areas where there is structurally complex vegetation than in those where the plant architecture is relatively simple. Biotic interactions rather than morphological constraints are considered to underlie this pattern. We investigated whether the preference of the larvae of the damselfly Enallagma cyathigerum for a particular habitat was retained in absence of prey, predators and/or conspecifics. A series of laboratory choice experiments was conducted in which combinations of sediment and artificial plants differing in structural complexity were offered simultaneously to the larvae. Larvae preferred patches with structurally complex vegetation over patches with simply structured vegetation or lacking vegetation. Patches with simply structured vegetation were preferred over those with bare sediment, but the number of larvae showing a clear choice, which is regarded as an indication of the strength of the preference for a particular habitat, was relatively low compared to the number of individuals responding when complex vegetation was present. Based on the results presented, we conclude that the preference of E. cyathigerum larvae for structurally complex vegetation is independent of the presence of predators, prey or competitors. This suggests that this behaviour of the larvae is either learned or an innate response.
\end{abstract}

\section{INTRODUCTION}

Habitat structure is an important factor in freshwater ecosystems, influencing the distribution of aquatic insects and other macro-invertebrates and affecting the outcome of biotic interactions (Bell et al., 1991; Jeffries, 1993; Warfe \& Barmuta, 2004, 2006). In general, macroinvertebrate abundance and number of taxa associated with structurally complex macrophytes is greater than with plants with a simple architecture (Cheruvelil et al., 2002; Taniguchi et al., 2003; Thomaz et al., 2008). Furthermore, the macro-invertebrate taxon richness recorded for substrates with a rough surface is greater than for substrates with smooth surfaces (Douglas \& Lake, 1994; Downes et al., 2000).

Zygoptera (Odonata) are an example of a macroinvertebrate group in which the larvae of most species appear to prefer habitats with a complex structure over those with a simple structure (Chilton, 1990; Lombardo, 1997; Schmude et al., 1998; Warfe \& Barmuta, 2006). Most damselfly larvae are classified as climbers, spending much of their larval life among macrophytes (Merritt \& Cummins, 1984). They are generalist predators, which are capable of switching between a sit-and wait feeding mode to catch mobile prey and active movement to catch slowly moving or sedentary prey (Koperski, 1997; Corbet, 1999). Odonata seem to be important in structuring aquatic communities (Thorp \& Cothran, 1984) since they can be abundant in lentic ecosystems and are often the numerically dominant predators of macro-invertebrates in beds of macrophytes.

There are several possible mechanisms that might explain the presence of larger numbers of larvae in habitats with a complex structure than those that are structurally simpler or un-vegetated. Habitat preference could also be resource-based, since the larvae may be attracted to habitats with a high diversity and abundance of prey (Chilton, 1990) or mainly present in macrophytes with an architecture in which they are most efficient in capturing prey (Walsh, 1995). Finally, larvae may use vegetation as a refuge from predators (Dionne et al., 1990; Tolonen et al., 2003; Warfe \& Barmuta, 2006) or because they are subject to less inter- or intra-specific competition in such habitats (Elkin \& Baker, 2000; Suutari et al., 2004). These explanations are not mutually exclusive, which is one of the difficulties encountered when the structural complexity of a habitat is used to explain the differential use of structurally simple and complex macrophytes by macro-invertebrates. Therefore, controlled separation of the effects of structural complexity, prey availability and predation is needed to clarify the various mechanisms determining habitat choice by damselfly larvae and macro-invertebrates in general.

The damselfly Enallagma cyathigerum (Charpentier, 1840 ) is a suitable species for determining the role of habitat structural complexity in habitat selection, because whilst its larvae in general prefer structurally complex vegetation, they can also be found in structurally simple 
TABLE 1. Results of the statistical analysis of the choice of larvae of Enallagma cyathigerum for either compartment A or $B$ with a sand (M) or coarse organic sediment (O), respectively in combination with different types of vegetation: complex (C), simple (S), no vegetation (-). Chi square Test of Homogeneity was used to test larval choice with $\mathrm{P}<0.05$, ns - not significant.

\begin{tabular}{|c|c|c|c|c|c|c|}
\hline \multicolumn{2}{|c|}{$\begin{array}{l}\text { Structure in } \\
\text { compartment }\end{array}$} & \multicolumn{2}{|c|}{$\begin{array}{l}\text { Sediment in } \\
\text { Compartment }\end{array}$} & \multirow[t]{2}{*}{$\chi^{2}$} & \multirow[t]{2}{*}{$\mathrm{df}$} & \multirow[t]{2}{*}{$P$} \\
\hline A & $\mathrm{B}$ & A & $\mathrm{B}$ & & & \\
\hline \multirow[t]{3}{*}{$\mathrm{C}$} & $\mathrm{C}$ & $\mathrm{O}$ & $\mathrm{O}$ & 1.31 & 4 & $0.883^{\mathrm{ns}}$ \\
\hline & & M & $\mathrm{O}$ & & & \\
\hline & & M & M & & & \\
\hline \multirow[t]{4}{*}{$\mathrm{C}$} & $\mathrm{S}$ & $\mathrm{O}$ & $\mathrm{O}$ & 15.21 & 9 & $0.085^{\mathrm{ns}}$ \\
\hline & & M & $\mathrm{O}$ & & & \\
\hline & & $\mathrm{O}$ & $\mathrm{M}$ & & & \\
\hline & & $\mathrm{M}$ & $\mathrm{M}$ & & & \\
\hline \multirow[t]{4}{*}{$\mathrm{C}$} & - & $\mathrm{O}$ & $\mathrm{O}$ & 12.83 & 9 & $0.171^{\mathrm{ns}}$ \\
\hline & & $\mathrm{M}$ & $\mathrm{O}$ & & & \\
\hline & & $\mathrm{O}$ & M & & & \\
\hline & & $\mathrm{M}$ & $\mathrm{M}$ & & & \\
\hline \multirow[t]{4}{*}{$S$} & - & $\mathrm{O}$ & $\mathrm{O}$ & 9.97 & 9 & $0.353^{\mathrm{ns}}$ \\
\hline & & M & $\mathrm{O}$ & & & \\
\hline & & $\mathrm{O}$ & M & & & \\
\hline & & $\mathrm{M}$ & $\mathrm{M}$ & & & \\
\hline \multirow[t]{3}{*}{$\mathrm{S}$} & $\mathrm{S}$ & $\mathrm{O}$ & $\mathrm{O}$ & 10.88 & 6 & $0.092^{\mathrm{ns}}$ \\
\hline & & $\mathrm{M}$ & $\mathrm{O}$ & & & \\
\hline & & $\mathrm{M}$ & $\mathrm{M}$ & & & \\
\hline \multirow[t]{3}{*}{-} & - & $\mathrm{O}$ & $\mathrm{O}$ & 12.22 & 6 & $0.065^{\mathrm{ns}}$ \\
\hline & & $\mathrm{M}$ & $\mathrm{O}$ & & & \\
\hline & & M & M & & & \\
\hline
\end{tabular}

vegetation as well as on bare sediments (Johannsson, 1978; Lombardo, 1997). This species is often the numerically dominant damselfly in oligo- to mesotrophic lentic waters at an early stage of succession (Schiel, 1998). Because the larvae can occur in very dense aggregations, without exhibiting evident spacing or agonistic behaviour, competitive exclusion is likely to be of minor importance (Chowdhury \& Corbet, 1989). Risk of predation, prey availability or capture efficiency are therefore most likely to be the main factors that determine the habitat preference of larvae of E. cyathigerum.

In this study, we investigated habitat selection by $E$. cyathigerum larvae in a situation where there are no prey, predators or competitors present, to test the hypothesis that larvae do not display a clear preference for structurally complex vegetation when studied in isolation, which should indicate whether biotic interactions influence their choice of habitat. Under laboratory conditions, we offered combinations of no vegetation, simple vegetation structures (stems) and complex vegetation structures (plants with finely dissected leaves) to larvae in two-choice experiments. Since the larvae can potentially make use of bare sediment (Johannsson, 1978) both mineral (smooth) and coarse organic (rough) sediments were included in this choice experiment.

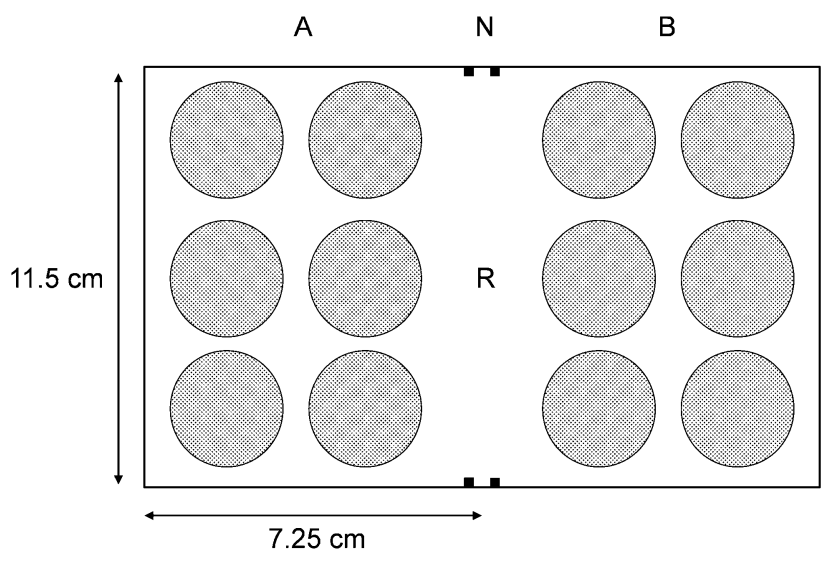

Fig. 1. Experimental container, divided in two compartments, left (A) and right (B). Circles represent the location of the artificial vegetation, which consisted of stems and/or artificial plants with finely dissected leaves. The bottom of the container was covered with sediment (sand and/or coarse organic sediment). To prevent the sediments from mixing when preparing the containers, a partition was inserted in the notches $(\mathrm{N})$ in the container wall. At the start of the experiment the partition was removed and the larva was released in the centre of the container $(\mathrm{R})$.

\section{MATERIAL AND METHODS}

\section{Test species}

E. cyathigerum is a Holartic species found in a broad variety of lentic ecosystems, e.g. ponds, lakes and ditches. The larvae used in the present study were collected from Kootwijkerveen $\left(52.207^{\circ} \mathrm{N}, 5.795^{\circ} \mathrm{E}\right)$, an acid, fishless heath land pool on sandy soils near Kootwijk, the Netherlands. Larvae were caught in a shallow part of the pool by sweeping a net $(1.0 \mathrm{~mm}$ mesh) through the macrophytes, which included both submerged plants with finely dissected leaves and emergent stems, and over the bottom sediment and were brought to the laboratory within 4 hours. In the laboratory, penultimate and final instars were selected for the experiment [average head width $2.7( \pm 0.24)$ $\mathrm{mm}, \mathrm{N}=336]$.

Each larva was placed in a separate PVC tube (height $8.5 \mathrm{~cm}$, diameter $4.0 \mathrm{~cm}$ ), to prevent larvae damaging each other. The lower end of the tube was closed with wire netting $(2 \mathrm{~mm}$ mesh). In each tube, a stem of Ceratophyllum demersum from a nearby pond was provided for perching. Tubes were placed in large containers, filled with approximately 121 of aerated ground water. The containers were stored in a climate room (12L : $12 \mathrm{D}$ photoperiod, temperature $16 \pm 1^{\circ} \mathrm{C}$ ). Every 3rd day, larvae were fed approximately 10 Daphnia magna per individual. The larvae were allowed to acclimatize to these conditions for one month. Larvae were fed with 10 Daphnia magna $4 \mathrm{~h}$ before the experiment started so that they were each similarly satiated. Following Jeffries (1990), recently moulted individuals or those showing pre-emergence characteristics were not used, because they could behave differently.

\section{Experimental design}

To determine the habitat preferences of E. cyathigerum larvae, 21 combinations (two types of sediment in combination with three types of vegetation: none, simple or complex) were tested using a total of 16 individuals per combination (Table 1). Pair wise combinations were provided in transparent plastic containers (length $14.5 \mathrm{~cm} \times$ width $11.5 \mathrm{~cm} \times$ height $7.3 \mathrm{~cm}$ ), which were divided into two compartments (Fig. 1). 
Each combination was tested in a separate container, which was filled with 0.751 aerated ground water. Depending on the treatment, the bottom of each compartment was covered with a $1 \mathrm{~cm}$ layer of well-washed fine sand (grain size 125-250 $\mu \mathrm{m}$ ) or black peat (particle size $1-10 \mathrm{~mm}$ ), which represented coarse organic sediment. Peat was washed thoroughly and sieved (1.0 $\mathrm{mm}$ mesh) in order to prevent fast re-suspension of small particles and discoloration of the water. A Plexiglas partition was used to prevent the mixing of the different substrates when filling the containers with water and was removed before the start of the experiment. The artificial plants used in the experiments differed in morphological complexity. The types of structural complexity were based on Warfe \& Barmuta (2006). The complex vegetation consisted of 6 leaf-bearing stems (length 6.0 $\mathrm{cm}$ ) of commercially produced artificial plants resembling Limnophila heterophylla (Tetra Plantastics, Melle, Germany) with 4 highly dissected leaves and the simple vegetation of 6 tufts of plastic coated wire, which resemble the cylindrical leaves and stems of Juncus. Each tuft consisted of 3 plastic-coated metal wires (diameter $1.5 \mathrm{~mm}$, length $6.0 \mathrm{~cm}$ ).

Assuming that larvae continually search for the best available habitat and spend most of their time there we recorded time spent in each habitat. At the start of the experiment, one larva was released in the centre of each container and was allowed to move around freely for $24 \mathrm{~h}$. After $6 \mathrm{~h}$ in the container, the light in the climate room was switched off for $12 \mathrm{~h}$. The next day, the light was switched on again for $6 \mathrm{~h}$. The first $18 \mathrm{~h}$ of the trial allowed the larva to get used to its new surroundings and then its position in the container was recorded in the following $6 \mathrm{~h}$. Pilot trials showed that there was little difference in position and behaviour at 12,24, 48 and $72 \mathrm{~h}$, and therefore 3 records of the position of the larvae in the last $6 \mathrm{~h}$ of the trial were used as an indication of habitat preference. Positions were recorded $1 \mathrm{~h}, 3.5$ $\mathrm{h}$ and $6 \mathrm{~h}$ after the light was switched on again $(\mathrm{n}=1008$ observations).

If present in the same compartment on all three occasions the habitat preference of the larva was designated a "clear choice". When present in compartments with vegetation, the majority of the larvae perched on the vegetation $(90 \%, \mathrm{n}=572$ observations). On the stems, larvae perched vertically, head downwards or upwards. On the complex vegetation, the larvae used the leaves, perching horizontally on top or on the lower side of a leaf, head facing outwards. If the larvae did not perch on the vegetation, they were present on the substrate directly underneath the vegetation (e.g. under the lower leaves of the complex plants). We regarded this behaviour as directly affected by the vegetation. Therefore, all larvae present in a compartment with vegetation were counted, whether perching on or beneath the structures.

\section{Statistical analyses}

First, the effect of substratum type on habitat choice was tested. Since macrophytes are the primary habitat of E. cyathigerum larvae under natural conditions, we tested if larval preference for a particular type of vegetation was influenced at all by the sediment provided in the compartments. This analysis was carried out using a Chi square test of homogeneity.

Subsequently, it was tested if the larvae displayed a preference for either a compartment of a pair in which the vegetation was the same or in which it was different. The former set of experiments represented a control; preference for a compartment would indicate a non-random influence of, for example, the container or room. To determine if the larvae preferred a particular type of vegetation, binomial tests were used. For each treatment (same vegetation in both compartments, $\mathrm{n}=48$ individuals tested; different vegetation in both compartments, $n=64$ ), the
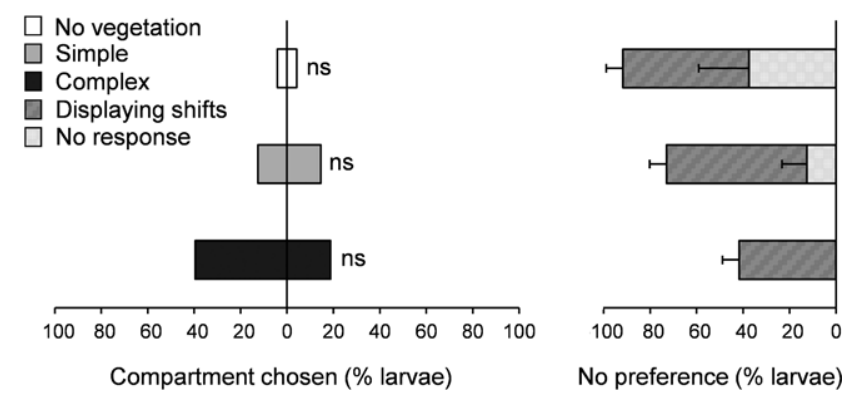

Fig. 2. Choice of compartment by larvae of Enalagma cyathigerum when there is the same vegetation in both compartments. Left figure shows the percentage of individuals that chose either the left or right compartment (ns = not significant, based on Binomial tests). Right figure shows the mean percentage $( \pm 1 \mathrm{SD})$ of individuals per treatment $(n=3)$ that did not show a preference and is divided to show the proportions of larvae that moved between compartments between observations ("displaying shifts") and of those that perched on the notches in the wall of the container ("no response").

number of times a clear choice was made for one of the compartments was tested against the number of times a clear choice was made for the other compartment, assuming an equal distribution $\left(\mathrm{P}_{\mathrm{A}}=\mathrm{P}_{\mathrm{B}}=0.5\right)$. The null hypothesis of no preference was rejected if one of the two compartments in a container was chosen more often, indicating that the larva did not chose randomly.

Besides the proportion of larvae that made a clear choice, we also recorded the proportion of non-responsive individuals (those that clung to one of the two notches in the container wall at the point of release; Fig. 1) per treatment as well as the proportion of individuals that did not show a preference (moved between the two compartments during the period of observation) as informative, because this behaviour could be an indication of the strength of the habitat preferences, following De Lange et al. (2005). Therefore, we tested for differences in the mean percentage of individuals showing no preference for either a compartment in a pair in which the vegetation in both compartments was the same or in which it was different. To determine the mean percentage of individuals showing no preference, the different substrate combinations were used as replicates ( $\mathrm{n}=3$ for the same vegetation in both compartments and $n$ $=4$ for different vegetation in the two compartments, Table 1). The analysis of the different vegetation treatments was carried out using a one-way analysis of variance (ANOVA), followed by a Tukey post-hoc comparison test $(n=4)$. For the analysis of the same vegetation treatment, a non-parametric Kruskal-Wallis test in combination with a Jonckheere-Terpstra test $(n=3)$ was used, because of deviations from normality. Significance level in all tests was set at $\mathrm{P}=0.05$. All statistical tests were performed in SPSS for Windows (version 15, SPSS inc.).

\section{RESULTS}

The type of substrate did not have a significant effect on larval behaviour (Table 1). The proportion of larvae that made a clear choice for either compartment as well as the proportion of larvae that moved between compartments or did not respond did not differ significantly between any of the substrate combinations. Therefore, all substrate combinations were grouped in further analyses.

When offered a choice between compartments with the same type of vegetation larvae showed no preference for 


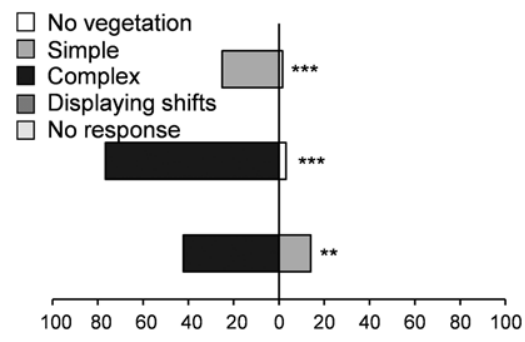

Compartment chosen (\% larvae)

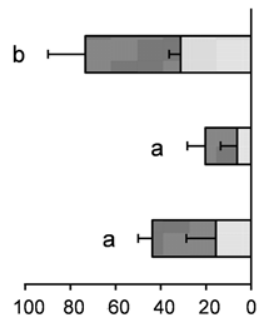

No preference (\% larvae)
Fig. 3. Choice of compartment by larvae of Enalagma cyathigerum when the vegetation in the two compartments is different. Left figure shows the percentage of individuals that chose either the left or right compartment ( $* * \mathrm{P}<0.01, * * * \mathrm{P}<$ 0.001 , based on Binomial tests). Right figure shows the mean percentage $( \pm 1 \mathrm{SD})$ of individuals per treatment $(n=4)$ that did not show a preference, divided as in Fig. 2. Lower case letters indicate homogeneous groups for total proportion of larvae without a preference (displaying shifts + no response; Tukey post-hoc comparison test, $\mathrm{P}<0.05$ ).

one of the compartments (Fig. 2). Nonetheless, the percentage of individuals per treatment that made a clear choice was significantly affected by the level of structural complexity of the vegetation $[\mathrm{H}(2)=6.359, \mathrm{P}=0.01$; Fig. 2]. Fewer larvae made a clear choice of compartments with simple or no vegetation (Jonckheere-Terpstra test: J $=1.5, \mathrm{z}=-2.70, \mathrm{P}=0.01)$.

When offered a choice between compartments with different types of vegetation the larvae preferred complex vegetation over simple and no vegetation, and simple vegetation over no vegetation (Fig. 3). The proportion of individuals that made a clear choice varied significantly between treatments (Fig. 3). The combined proportion of non-responding larvae and those shifting between compartments was significantly higher in the combination with simple vegetation and no vegetation than in other combinations $\left(\mathrm{F}_{2,9}=15.02, \mathrm{P}=0.001\right)$.

\section{DISCUSSION}

Active selection of structurally complex vegetation by the larvae of E. cyathigerum in this experiment is consistent with the findings of Chilton (1990) and Lombardo (1997), who observed that under natural conditions Enallagma larvae were most numerous on structurally complex macrophytes and less abundant on plants with a simple leaf architecture. We show that preference for vegetation with a complex structure did not change when the larvae were removed from their natural habitat and placed in an environment without predators, prey and con-specifics. This contrasts with reports of the behaviour of other species of Odonata, in which habitat preferences of the larvae change in the absence of biotic interactions (Heads, 1986; Elkin \& Baker, 2000; Suutari et al., 2004).

Preference for vegetation with a particular structure is, at least to a certain extent, the result of morphological and behavioural characteristics of the species, assuming that larvae actively select habitats to which they are adapted. For example, to be able to catch prey, damselfly larvae need a rigid structure to hang on to in order to counteract the backward movement generated when their labium protracts (Corbet, 1999). As a consequence, bare sediments are unsuitable for capturing prey. Therefore, it is not surprising that larvae preferred compartments with vegetation over those with just sediment, but their specific preference for vegetation with a complex structure is puzzling as other damselfly larvae are equally attracted to both simple and complex vegetation (Lombardo, 1997). This suggests that, despite the absence of predators and prey in our experiment, both factors may have influenced the behaviour of the larvae of E. cyathigerum studied.

Since damselfly larvae tend to stay near areas where food is abundant (Baker, 1981), it is possible that they prefer to perch in vegetation where they foraged efficiently most of their lives. Vegetation with a complex structure is abundant in the heathland pool from which the larvae originated. In general, macro-invertebrate abundance, total biomass and species richness are higher in structurally complex habitats (Jeffries, 1993; Warfe \& Barmuta, 2006; Thomaz et al., 2007). When an abundance of a large variety of prey species is available damselfly larvae are able to choose between prey items and capture prey with fewer capture attempts, resulting in faster growth and development and larger biomass at emergence (Heads, 1986; Schaffner \& Anholt, 1998). This suggests that patches of complex vegetation are a more favourable location for the prey of damselfly larvae than are macrophytes with a simple architecture, particularly because Enallagma larvae are equally efficient at capturing prey in structurally simple and complex vegetation (Lombardo, 1997).

Furthermore, complex vegetation offers better protection against predators, particularly fish, than structurally simple vegetation and the increasing tendency of damselfly larvae to hide in vegetation with increase in predation risk suggests that they are able to recognize high and low risk environments (Dionne et al., 1990). The role of structural complexity in mediating invertebrate predatorprey interactions, which is more relevant for this study because the larvae used in our experiment only co-existed with invertebrate predators, is less clear. Trade-offs between optimizing growth and avoiding predation through habitat choice are well known in both aquatic and terrestrial ecosystems (Werner \& Gilliam 1984; Werner \& Anholt, 1994). Responses to cues from invertebrate predators, studied in complex vegetation or artificial analogs, seem to depend on the identity of the predator and the presence of prey. Jeffries (1990), for example, observed that the larvae of E. cyathigerum moved less when a larva of Aeshna juncea was present, but only in the absence of food. When both invertebrate predators ( $A$. juncea, Notonecta glauca) and prey are present, feeding and movement rates of the larvae are not or only weakly suppressed (Chowdhury \& Corbet, 1988; Jeffries, 1990; Koperski, 1997). An exception are the chemical cues produced by Ranatra linearis, which strongly reduce larval feeding rates (Koperski, 1997). Therefore, it is possible that the larvae used in our experiment were predisposed to avoid predators by selecting structurally complex habi- 
tats and continue to use the habitat with the highest refuge value even when predators are not present, because it was a successful strategy during the earlier stages of their development.

There was a clear relationship between the number of larvae not showing a preference for vegetation and habitat structural complexity. In the absence of complex vegetation, the number of larvae moving between compartments increased considerably. This is possibly because the larvae try to locate suitable perching sites. When complex vegetation was present, the number of larvae showing no choice decreased considerably, which further supports their preference for macrophytes with a complex architecture. A fraction of the larvae immediately perched in the notches on the container walls and remained there throughout the trial. Apparently, these notches also offered a perching opportunity for the larvae and with decrease in habitat complexity appeared to be more often selected. Since this container effect paralleled the pattern in larvae without a preference, it did not affect the outcome of the experiment.

In conclusion, larvae of E. cyathigerum actively selected structurally complex vegetation over simple vegetation or bare sediment. This preference was demonstrated in an environment without predators, prey or conspecifics. Future studies are needed to determine whether this response is the result of learned behaviour or an innate, evolved response. One way to answer this question would be to repeat the experiment using laboratoryreared larvae that were previously reared in containers with different types of vegetation or cues of the presence of predators instead of field-collected larvae.

ACKNOWLEDGEMENTS. We would like to thank J. Beijer for his help with the experiment, D. Groenendijk and J. Bouwman (Dutch Butterfly Conservation) for sharing with us their knowledge of Odonata, W. Huijsman (Staatsbosbeheer) for providing access to the nature reserve where the larvae were collected and anonymous reviewers for their valuable comments and suggestions. This study was supported by the Foundation of Applied Water Research (STOWA) (PLONS-project) and the strategic research program "Sustainable spatial development of ecosystems, landscapes, seas and regions" which is funded by the Dutch Ministry of Agriculture, Nature Conservation and Food Quality (KB-01-002-007-ALT).

\section{REFERENCES}

BAKER R.L. 1981: Behavioural interactions and use of feeding areas by nymphs of Coenagrion resolutum (Coenagrionidae: Odonata). Oecologia 49: 353-358.

Bell S.S., McCoy E.D. \& Mushinsky H.R. 1991: Habitat Structure: The Physical Arrangement of Objects in Space. Chapman and Hall, London, 438 pp.

Cheruvelil K.S., Soranno P.A., Madsen J.D. \& Roberson M.J. 2002: Plant architecture and epiphytic macroinvertebrate communities: the role of an exotic dissected macrophyte. $J$. N. Am. Benthol. Soc. 21: 261-277.

Chilton E.W. 1990: Macroinvertebrate communities associated with 3 aquatic macrophytes (Ceratophyllum demersum, Myriophyllum spicatum and Vallisneria americana) in lake Onalaska, Wisconsin. J. Freshwater Ecol. 5: 455-466.
Chowdhury S.H. \& Corbet P.S. 1988: Feeding rate of larvae of Enallagma cyathigerum (Charpentier) in the presence of conspecifics and predators (Zygoptera: Coenagrionidae). Odonatologica 17: 115-119.

Chowdhury S.H. \& Corbet P.S. 1989: Feeding-related behaviour in larvae of Enallagma cyathigerum (Charpentier) (Zygoptera: Coenagrionidae). Odonatologica 18: 285-288.

Corbet P.S. 1999: Dragonflies. Behaviour and Ecology of Odonata. Cornell University Press, Ithaca, NY, $829 \mathrm{pp}$.

De Lange H.J., Lürling M., Van den Borne B. \& Peeters E.T.H.M. 2005: Attraction of the amphipod Gammarus pulex to water-borne cues of food. Hydrobiologia 544: 19-25.

Dionne M., Butler M. \& Folt C. 1990: Plant specific expression of antipredator behaviour by larval damselflies. Oecologia 83: 371-377.

Douglas M. \& LaKe P.S. 1994: Species richness of stream stones: an investigation of the mechanisms generating the species-area relationship. Oikos 69: 387-396.

Downes B.J., Lake P.S., Schreiber E.S.G. \& Glaister A. 2000: Habitat structure, resources and diversity: the separate effects of surface roughness and macroalgae on stream invertebrates. Oecologia 123: 569-581.

ELKIN C.M. \& BAKER R.L. 2000: Lack of preference for lowpredation-risk habitats in larval damselflies explained by costs of intraspecific interactions. Anim. Behav. 60: 511-521.

Heads P.A. 1986: The costs of reduced feeding due to predator avoidance: potential effects on growth and fitness in Ischnura elegans larvae (Odonata, Zygoptera). Ecol. Entomol. 11: 369-378.

JEFFRIES M. 1993: Invertebrate colonization of artificial pondweeds of differing fractal dimension. Oikos 67: 142-148.

JEFFRIES M. 1990: Interspecific differences in movement and hunting success in damselfly larvae (Zygoptera: Insecta): responses to prey availability and predation treat. Freshwater Biol. 23: 191-196.

JoHANnsson O.E. 1978: Co-existence of larval Zygoptera (Odonata) common to the Norfolk Broads (U.K.). I. Temporal and spatial separation. Oecologia 32: 303-321.

KOPERSKI P. 1997: Changes in feeding behaviour of the larvae of the damselfly Enallagma cyathigerum in response to stimuli from predators. Ecol. Entomol. 22: 167-175.

Lombardo P. 1997: Predation by Enallagma nymphs (Odonata, Zygoptera) under different conditions of spatial heterogeneity. Hydrobiologia 356: 1-9.

Merritt R.W. \& Cummins K.W. 1984: An Introduction to the Aquatic Insects of North America. 2nd ed. Kendall/Hunt publishing company, Dubuque, IA, 722 pp.

SCHAFFNER A.K. \& ANHOLT B.R. 1998: Influence of predator presence and prey density on behavior and growth of damselfly larvae (Ischnura elegans) (Odonata: Zygoptera). $J$. Insect Behav. 11: 793-809.

Schiel F. 1998: Zur Habitatbindung der Becher-Azurjungfer (Enallagma cyathigerum Charpentier 1840) (Odonata: Zygoptera) am südlichen Oberrhein. Natursch. Südl. Oberrh. 2: 139-147.

Schmude K.L., Jennings M.J., Otis K.J. \& Piette R.R. 1998: Effects of habitat complexity on macroinvertebrate colonization of artificial substrates in northern lakes. J. N. Am. Benthol. Soc. 17: 73-80.

SuUtari E., Rantala M.J., Salmela J. \& Suhonen J. 2004: Intraguild predation and interference competition in the endangered dragonfly Aeshna viridis. Oecologia 140: 135-139.

TANiguchi H., Nakano S. \& ToKeshi M. 2003: Influences of habitat complexity on the diversity and abundance of epiphytic invertebrates on plants. Freshwater Biol. 48: 718-728. 
Thomaz S.M., Dibble E.D., Evangelista L.R., Higuti J. \& Binı L.M. 2008: Influence of aquatic macrophyte habitat complexity on invertebrate abundance and richness in tropical lagoons. Freshwater Biol. 53: 358-367.

THORP J.H. \& CоTHRAN M.L. 1984: Regulation of freshwater community structure at multiple intensities of dragonfly predation. Ecology 65: 1546-1555.

Tolonen K.T., Hämäläinen H., Holopainen I.J., Mikkonen K. \& KARJALAINEN J. 2003: Body size and substrate association of littoral insects in relation to vegetation structure. Hydrobiologia 499: 179-190.

WALSH E.J. 1995: Habitat-specific predation susceptibilities of a littoral rotifer to two invertebrate predators. Hydrobiologia 313/314: 205-211.
WARFe D.M. \& BARMUTA L.A. 2004: Habitat structural complexity mediates the foraging success of multiple predator species. Oecologia 141: 171-178.

WARFE D.M. \& BARMUTA L.A. 2006: Habitat structural complexity mediates food web dynamics in a freshwater macrophyte community. Oecologia 150: 141-154.

WERNER E.E. \& ANHOLT B.R. 1994: Ecological consequences of the trade-off between growth and mortality rates mediated by foraging activity. Am. Nat. 142: 242-272.

Werner E.E. \& Gilliam J.F. 1984: The ontogenetic niche and species interactions in size-structured populations. Annu. Rev. Ecol. Syst. 15: 393-425.

Received June 1, 2011; revised and accepted January 4, 2012 